\title{
Trusting Only Whom You Know, Knowing Only Whom You Trust: The Joint Impact of Social Capital and Trust on Happiness in CEE Countries
}

\author{
Katarzyna Growiec · Jakub Growiec
}

Published online: 17 August 2013

(C) The Author(s) 2013. This article is published with open access at Springerlink.com

\begin{abstract}
We investigate the extent to which bridging and bonding social capital as well as social trust and individuals' earnings interdependently affect self-reported happiness. The study is based on cross-sectional World Values Survey 2000 data on individuals from eight Central and Eastern European countries (CEECs). We identify high risk of regressor endogeneity and omitted variables bias in happiness regressions, and eliminate them using instrumental variables and an appropriate set of controls. The endogeneity issue has been generally overlooked in earlier studies. Our study therefore provides novel implications for the general discussion on the causal relationships between the five considered variables. Our results are also discussed in the specific context of socio-economic convergence processes currently taking place in CEECs.
\end{abstract}

Keywords Happiness · Bridging social capital · Bonding social capital · Social trust $\cdot$ Earnings $\cdot$ CEE countries

\section{Introduction}

It is widely agreed in the literature that social capital and trust can have sizeable effects on individuals' happiness. This general finding has been confirmed in a wide range of

\footnotetext{
K. Growiec

Department of Psychology of Personality, University of Social Sciences and Humanities, ul. Chodakowska 19/31, 03-815 Warsaw, Poland

e-mail: katarzyna.growiec@swps.edu.pl

J. Growiec $(\square)$

Institute of Econometrics, Warsaw School of Economics, al. Niepodległości 162, 02-554 Warsaw,

Poland

e-mail: jakub.growiec@sgh.waw.pl

J. Growiec

Economic Institute, National Bank of Poland, Warsaw, Poland
} 
studies - surveyed further in the paper-based on a variety of empirical approaches as well as for various countries. The debate on the relative strength of links between these variables, and whether they have a causal character or not, is however far from resolved. In particular, numerous scholars have argued in this respect that Putnam's (2000) distinction between bridging social capital (social ties with dissimilar others) and bonding social capital (social ties with similar others) might be useful in describing differential impacts of various types of social capital on individuals' happiness. In line with this strand of literature, we shall operationalize bridging and bonding social capital via the characteristics of individuals' social networks (Lin 2001), distinguishing between ties with kin and non-kin.

The current paper addresses the discussion on the relationship between social capital, trust, and happiness by providing certain novel results based on World Values Survey (WVS) data from Central and Eastern European countries (CEECs), ${ }^{1}$ with a twofold contribution to the literature. First and foremost, we investigate the extent to which individuals' social networks affect their happiness in CEECs, controlling for income, education, employment status, as well as a range of other underlying socio-economic characteristics. We shall exploit the fact that bridging social capital and trust levels are extremely low in the considered group of countries, which allows us to verify if people there really "trust only whom they know, and know only whom they trust", and if this impacts their happiness. We confirm a positive effect of both bridging and bonding social capital on self-reported happiness even after the effects of income disparities and other variables are neutralized. Our paper can thus improve the understanding why CEECs, on average, lag behind EU-15 not only economically, but also in terms of happiness.

The second contribution of this paper to the literature is a methodological one: by applying a number of instrumental variables (IV) regressions, controlling for endogeneity of regressors and potential omitted variables bias, and carefully testing the validity and identification properties of instruments used in each regression specification, we sort out several empirical caveats arising in the related literature due to the endogeneity of social capital and earnings in happiness regressions. To strengthen this point, we also include two robustness checks. First, we discuss the impacts of social capital and trust on the WVS measure of life satisfaction (which has a more persistent, cognitive character than happiness). We proceed to apply the instrumental variables ordered probit estimation technique, aimed at capturing the discrete character of the WVS happiness variable. Reassuringly, we find that our main results are fully robust to both these modifications.

Thanks to this last feature of our analysis, the current paper can be viewed as a general methodological contribution to the debate on the causal relationships between social capital, trust, individuals' earnings, and happiness, reaching beyond the specificity of CEE countries. We emphasize that the empirical methodology for testing certain hypotheses should be chosen appropriately given the available dataset. Our results indicate that some empirical regularities, even when supported by theory, might nevertheless disappear in certain samples (e.g., in specific groups of countries), whereas others might not be robust to controlling for variable endogeneity.

At this point please note that, although often disregarded in happiness research, the endogeneity of social capital with respect to happiness has in fact been already documented in a range of studies. In particular, Diener and Seligman (2002) have found that happier individuals tend to spend less time alone and more time socializing compared to less happy people. Happy people are also more satisfied with their family relations, romantic partner

${ }^{1}$ In the case of the current paper, this category encompasses Poland, the Czech Republic, Slovakia, Hungary, Slovenia, Lithuania, Latvia, and Estonia. 
and close friends. These authors argue that good social relationships are likely a necessary condition for high happiness (i.e., happiness likely implies good social relationships): all members of their "very happy" group reported good-quality social relationships. Complementing to this research, Alesina and Giuliano (2010) have found that family ties are generally stronger in happier societies. Finally and most importantly, Christakis and Fowler $(2009 \mathrm{a}, \mathrm{b})$ have documented that happier people are typically more central to the social network, whereas the unhappy ones are more often found in the social network periphery. People tend to cluster with others who have similar levels of happiness, and happier individuals maintain more social ties. For these reasons, supported by the results of statistical endogeneity tests carried out for our dataset, we believe that social capital should be generally perceived as endogenous in happiness regressions.

We also interpret our results in relation to the hypothesis that extremely low levels of bridging social capital and trust, formed in CEECs in their communist and transition years, might slow down their socio-economic catch-up with the EU-15. The mechanism investigated here is based on the conjecture that citizens of CEECs may be trapped in a low bridging social capital-low trust equilibrium where forming social ties with dissimilar people is discouraged by the lack of general trust, and conversely-forming social trust is hampered by little social exposure-thus generating a vicious circle (Growiec and Growiec 2013). A complementary hypothesis is that bonding social capital works against quick modernization and socio-economic development. As opposed to bridging social capital, the experiences of CEECs with respect to bonding social capital are quite mixed, though.

The remainder of the paper is structured as follows. Section 2 discusses the background literature. Section 3 discusses measurement issues and presents the preliminary evidence on the patterns of social capital, trust, and self-reported happiness in CEECs, highlighting the similarities and differences between them. It thereby provides the foundations for our main hypotheses, thoroughly tested in Sect. 4. Section 5 presents two additional robustness checks. Section 6 views our results against the established literature, drawing some interesting inferences. Section 7 concludes.

\section{Related Literature}

Conceptually, the current paper relates to four complementary strands of sociological and psychological literature. The first of them is preoccupied with the definition and measurement of social capital. We build on the principal idea to operationalize bridging and bonding social capital via the characteristics of individuals' social networks (Lin 2001). Such an approach is especially fruitful analytically, because it enables one to delineate people's objective behavior (maintaining social contacts with others) from social norms (trust, reciprocity). The social network perspective on social capital is widely shared (Lin 2001; Kadushin 2002; Li et al. 2005; Burt 2005); moreover, this position leads to being more specific on social networks people form and, as a consequence, to what resources they have access (Bourdieu 1986; Lin 2001). Putnam's (2000) distinction between bridging social capital (social ties with dissimilar others) and bonding social capital (social ties with similar others) has by now become a standard in social capital studies; on the other hand, there is still little congruence in the literature on the appropriate empirical method of social capital measurement, partly driven by the lack of sufficiently close proxies in large-scale survey datasets such as the WVS used here. In micro-level analyses, bridging (respectively, bonding) social capital is often measured as the frequency of social contact with people in a different (respectively, similar) social-economic position to oneself. When adopting such 
an approach in studies at the national and international level, there always remains the problem of data availability, though. To overcome this difficulty, some authors have argued that bonding social capital can be alternatively operationalized as the strength of family ties and the tendency to form kinship groups based on unconditional loyalty (Kääriäinen and Lehtonen 2006; Alesina and Giuliano 2010). In line with this logic, the current empirical study shall rely on a proxy operationalization of bonding social capital via declarations of importance of family in one's life and the parent-child relationship model that one holds.

The second strand of related literature deals with general trust. Arguably, modern societies are more then ever based on general trust and social interactions (Simmel 1971; Giddens 1991; Sztompka 1999; Yamagishi 2002; Glanville and Paxton 2007; Klapwijk and Van Lange 2009); without trust societies would disintegrate as trust is a synthetic force within the society (Simmel 1950; Putnam et al. 1993). At the same time, general trust turns out to be closely related to bridging social capital while distrust-with bonding social capital; previous findings show that there are mutually reinforcing relationships between social capital and general trust (Growiec 2009, 2011). At the individual level, people whose prevailing form of social capital is the bonding one are significantly more likely to present general distrust than those with abundant bridging social capital. These regularities are also present in our data, driving some of our regression results.

The third strand of related theoretical literature deals with the joint impact of social capital and trust on economic performance and happiness at the level of individuals, communities, regions, and whole countries. Some sociologists argue that bridging social capital, as opposed to bonding social capital, goes together with civil liberties and the support for gender and racial equality, and strengthens the functioning of democracy by reducing corruption (Putnam et al. 1993; Putnam 2000). On the other hand, "bonding social capital (...) has negative effects for society as a whole, but may have positive effects for the members belonging to this closed social group or network" (Beugelsdijk and Smulders 2003).

Bridging social capital is also found to be individually beneficial for those who possess it. Granovetter's (1973) prominent discovery is that weak ties (i.e., ties between dissimilar people) are more useful for finding better jobs than strong ties (between similar people). Friendship ties have also been shown to be positively related to individuals' wages and upward mobility in the workplace (Podolny and Baron 1997; Słomczyński and TomescuDubrow 2005). Most strongly perhaps, Burt (2005) claims that bridging social capital, as opposed to bonding social capital, is positively related to individuals' economic performance, creativity, social trust, and happiness. Our analysis emphasizes a further important piece of this puzzle: social networks are endogenous both to individuals' economic position and happiness.

Despite Burt's (2005) clear suggestions that bridging social capital should be positively related to individuals' happiness, the issue of whether social networks causally influence happiness has not been fully settled either. Even more worryingly, earnings and happiness are directly interrelated as well, complicating the matter even further (Helliwell 2003): people with higher relative incomes have been found to show significantly higher measures of subjective well-being (Diener et al. 1999). It could also be true that these ambiguous results were due to a non-linear relation between happiness (or subjective well-being) and income: "Theory and some previous research suggest that the effects of individual and national incomes may be non-linear in nature, with smaller well-being effects attached to increases in income beyond levels set by each individual's or society's expectations and habits" (Helliwell 2003, p. 344). Our findings for CEECs confirm positive happiness 
effects of both bridging and bonding social capital, even when their endogeneity as well as other variables such as individuals' incomes, employment status and social trust are carefully controlled for.

Fourthly, in a closely related paper (Growiec and Growiec 2013) we have put forward a theoretical model aimed at capturing the hypothesis that bridging social capital and social trust can form both virtuous and vicious circles, leading to multiple equilibria in economic performance. In the current contribution, we have tested these predictions empirically by checking the signs and statistical significance of interaction terms between both types of social capital, trust, and employment status, leading to mixed results. These findings have to be treated with caution, though, because it is difficult to find strong instruments for the interaction terms.

\section{Measurement and Preliminary Evidence}

Our study is based on data from the WVS, which is an international survey program based on a standardized questionnaire. The survey is conducted in each member country by a local public opinion survey institution, in the local language, on a representative sample of the country's population aged $18+$, in the same year $( \pm 1$ year). Sample sizes vary around 1,000 respondents per country, regardless of country size. There are however numerous gaps in data regarding some variables, including the ones used for constructing our social capital measures. As far as we were able to check, these gaps don't exhibit any systematic pattern within countries. However, as regards the country coverage of the current study, Baltic countries have by far most missing observations. In particular, for the most datademanding instrumental variables regresions discussed here, we could use about 3,800 observations in total, including around 900 observations from the Czech Republic, 700 from Poland, Slovakia and Hungary, and only 50 observations from Latvia and 80 from Estonia. $^{2}$

Throughout our empirical analysis, we make use of data from the 2000 wave of the WVS only. The choice of this particular wave is due to the fact that only the 2000 wave of the WVS includes an extended list of questions relevant to the measurement of social capital. We can thus provide a sufficiently accurate description of the bridging and bonding social capital variables in CEECs only for 2000.

\subsection{Measurement of Social Capital and Trust}

Bridging Social Capital refers to forming social ties across social cleavages and requires people to transcend their simple social identity (Putnam 2000; Leonard 2008). For this reason, we operationalize this variable as time investments in socializing with friends, colleagues from work, friends from church, sports clubs, voluntary organizations, etc. Our bridging social capital measure is constructed as a summary scale based on the following questions:

- "How often do you spend time with your friends", answers: weekly, once or twice a month, only a few times in a year, not at all.

\footnotetext{
2 These numbers also explain why conducting our IV study on a country-by-country basis might lead to unreliable results (very high standard errors, few significant variables). These results are available from the authors upon request but are not reported here.
} 
- "How often do you spend time socially with your colleagues from work or your profession", answers: weekly, once or twice a month, only a few times in a year, not at all.

- "How often do you spend time with people at your church, mosque or synagogue", answers: weekly, once or twice a month, only a few times in a year, not at all.

- "How often do you spend time socially with people at sports clubs, voluntary or service organization", answers: weekly, once or twice a month, only a few times in a year, not at all.

We sum up the numeric values of answers (1-4) to these four survey questions and apply a normalizing linear transformation such that for each respondent, the resultant summary scale takes one of 13 available values ranging from 0 (all questions answered "not at all") to 1 (all questions answered "weekly"). The choice of this summary scale is optimal in the sense that the Cronbach's alpha analysis shows that its validity cannot be improved by removing any of its constituent items.

At this point, an insightful reader might notice that our measure of bridging social capital includes, among other information, also the frequency of contacts with close friends and fellow churchgoers. From the theoretical point of view, these contacts should arguably be rather classified as bonding, not bridging social capital; in line with this reasoning, Kääriäinen and Lehtonen (2006) included frequency of contact with close friends as well as the number of such social ties in their bonding social capital measure. In WVS data, however, there is no way to distinguish between contacts with close friends and other friends. The general notion of "friends" used in WVS is in our view a sufficiently wide category to be identified as bridging rather than bonding social capital because it is arguably likely to contain a large fraction of ties with dissimilar others-in line both with Putnam (2000) and Burt's $(2005,2010)$ notion of "brokerage" related to obtaining access to new valuable information, as opposed to "closure" related to obtaining unconditional support (which characterizes bonding social capital). In fact the quoted paper by Kääriäinen and Lehtonen (2006) follows essentially the same logic: as these authors argue, "[t]he concept of bonding social capital refers to strong ties among family members, friends or tightly structured ethnic or religious groups. These kinds of networks bind their members tightly together and they can be efficient in producing social support and control but they can also be exclusive towards other people outside the network. Strong ties can also be suffocating from the viewpoint of the network members. Bridging social capital refers to weaker social networks; they are not as tight and dense as bonding networks but they enable broader interaction and provide opportunities to develop social interaction that benefits individuals."

Bonding Social Capital is operationalized here on the basis of kinship ties. We construct it as a scale of WVS questions measuring the importance of family in one's life (very important, rather important, not very important, not at all important), the perception of parents' duties to their children (the respondents had to choose between the following statements: "It is parents' duty to do their best for their children" or "Parents have a life of their own"), and the opinion about the respect and love children owe their parents regardless of parents' deeds (the pair of statements: "Regardless of what the qualities and faults of one's parents are, one must always love and respect them" or "One does not have the duty to respect and love the parents who have not earned it by their behavior and attitudes").

We apply a normalizing linear transformation to the numeric values of answers to each of the aforementioned three questions (originally 1-4 for the first question, 1-2 for the 
other two) such that 0 denotes "not at all important", "life of their own", "one does not have the duty", respectively, and 1/3 denotes the other extreme. We then add the three numbers up. In result, for each respondent the summary scale of bonding social capital can take one of the 8 numeric values ranging from 0 to 1 . Again, analyzing this summary scale reveals that its validity cannot be improved by removing any of the items.

It must be noted that our empirical operationalization of bonding social capital simplifies the original Putnam's (2000) theoretical concept by limiting it to kinship ties. Such ties clearly belong to the concept, but other types of social ties-such as the aforementioned relationships with close friends, for which we do not have specific data-might belong there as well. Hence, even though our empirical approach is supported by a host of related literature, it is only a proxy operationalization. Moreover, in the case of bonding social capital we work with a measure of attitudes because, unfortunately, no relevant variables measuring actual behaviors of respondents are available in the WVS dataset. The worry that attitudes and actions might not be perfectly correlated is a valid one but we have no means to address it.

We simultaneously monitor the mean level of social trust in each society, measured by the frequency of affirmative answers to the survey statement: "Most people can be trusted" (as opposed to "Can't be too careful"). We distinguish between individuals' self-reported level of trust towards strangers and the degree to which they themselves are trusted. As a proxy measure of the latter, we use the average level of trust in the individuals' reference group. Individuals are stratified by their country of residence and education level.

\subsection{Measurement of Earnings and Other Control Variables}

The measure of individuals' earnings which we shall use in our regressions is the WVS scale of incomes per person in the household, with 10 available intervals for the respondents to pick. The scale of incomes has country-specific income thresholds, given in the local currency. Fortunately, an approximately logarithmic scale of incomes is maintained for all countries.

Apart from these variables, we shall also include several other measures ${ }^{3}$ from the WVS in our empirical regressions, potentially useful for explaining happiness directly, or for instrumenting the endogenous measures of bridging and bonding social capital.

\subsection{Measurement of Happiness}

The dependent variable in the current study is individuals' happiness. In (inverted) WVS 2000 data, this is captured by answers to the survey question: "Taking all things together, would you say you are", with 4 available answers: "very happy" (3), "quite happy" (2), "not very happy" (1), "not at all happy" (0).

In a robustness check to our main study, we have also taken life satisfaction as our dependent variable. WVS captures this dimension of individual well-being with the survey question: "All things considered, how satisfied are you with your life as a whole these days?", with 10 available answers ranging from 1 (dissatisfied) to 10 (satisfied).

\footnotetext{
3 The list includes: gender, age, age ${ }^{2}$, employment status, student status, housewife status, size of town of residence, household size (number of adult persons in the household aged 18+), being in a stable relationship, the sense of autonomy the individual perceives to have over her own life, participation in professional organizations, sports and recreation organizations or education and arts organizations, and the importance of religion and politics in her life.
} 
This last robustness check is motivated by the argument raised, among others, by Gamble and Gärling (2012), that life satisfaction captures a more long-term component of individual's well-being than happiness. Since social capital is also very persistent across individuals' lifetimes (e.g., Putnam 2000; Fidrmuc 2012), it might be interesting to look at the impacts of social capital on life satisfaction as well. In our data sample, both variables are rather strongly correlated, though (Spearman rank correlation amounts to 0.466).

Histograms of the four key variables included in our regressions (bridging and bonding social capital, happiness, life satisfaction) are presented in Fig. 1.

Having described our operationalization of the most important variables of the current study, and before we plunge into the main empirical investigation, we shall now present some of the basic properties of our data.

\subsection{Correlations at the Individual Level}

In agreement with the established literature (see Sect. 2), we observe significant individuallevel correlations between bridging social capital, bonding social capital, social trust, and happiness among CEECs' societies.

As we see in Table 1, bridging social capital and trust are positively and robustly correlated, both in the aggregate dataset and within each of the eight CEECs (that is, controlling for country dummies), even if a wide range of additional control variables is included. These controls include, first and foremost, bonding social capital, and also income per adult person in the household, size of town of residence, education, gender, the stable relationship dummy, age, age ${ }^{2}$, and subjectively reported happiness. Even though all
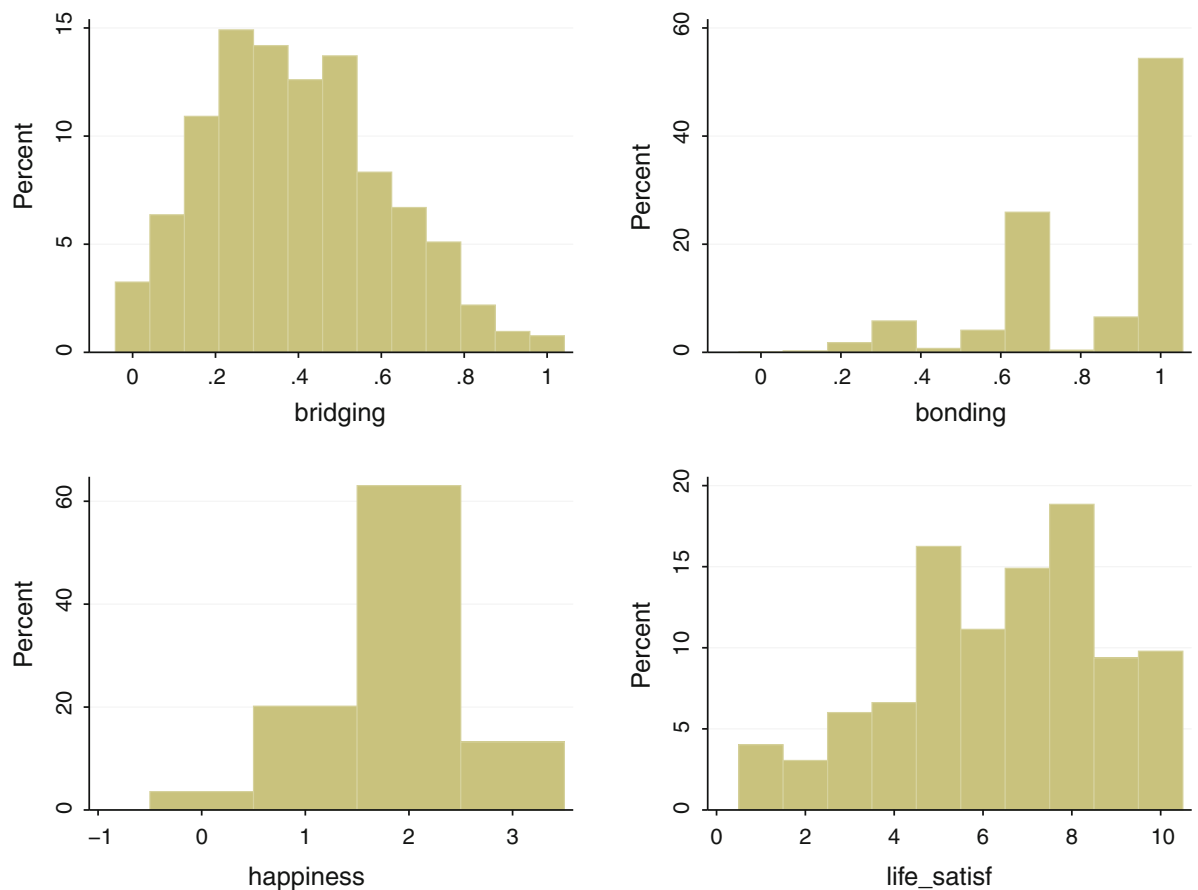

Fig. 1 Histograms of main variables of interest: bridging social capital, bonding social capital, happiness, and life satisfaction 
Table 1 Spearman rank correlations and partial correlations

Table 2 Spearman rank correlations and partial correlations

Table 3 Pearson correlations and partial correlations

\begin{tabular}{lll}
\hline Bridging social capital versus trust & & \\
\hline Controls & Corr. & $p$ value \\
\hline None & 0.078 & 0 \\
Bonding & 0.074 & 0 \\
Bonding + country dummies & 0.092 & 0 \\
Range of controls & 0.074 & 0 \\
Range of controls + happiness & 0.062 & 0 \\
\hline
\end{tabular}

\begin{tabular}{lcc}
\hline Bonding social capital versus trust & & \\
\hline Controls & Corr. & $p$ value \\
\hline None & -0.01 & 0.137 \\
Bridging & -0.015 & 0.285 \\
Bridging + country dummies & 0.001 & 0.947 \\
Range of controls & 0.024 & 0.113 \\
Range of controls + happiness & 0.022 & 0.148
\end{tabular}

these correlation coefficients are statistically significant, it must be said that they are quantitatively small, $<0.1$. The potential reasons for this result are the unobserved heterogeneity of respondents, and very noisy measurement of trust, captured by a single survey question.

In Table 2 we demonstrate that bonding social capital is, on the contrary, essentially uncorrelated with social trust. The raw correlation coefficient is negative but insignificant, and partial correlation controlling for bridging social capital and country dummies is zero. A further addition of the above-described range of controls makes the coefficient positive, yet still insignificant at the $10 \%$ level. This confirms that we should not seek a consistent relationship between bonding social capital and trust in CEECs where trust levels are generally very low.

Table 3 confirms that bridging and bonding social capital are distinct phenomena not only in their relationship with social trust, but also in their own mutual correlation. This correlation is marginal in the whole sample, essentially zero within countries, and significantly positive but $<0.05$ if a range of controls (income per adult person in the household, size of town of residence, education, gender, the stable relationship dummy, 
age, age $^{2}$, happiness) is added to the regression. This confirms that, despite caveats arising due to data availability problems, our approach to measurement is successful in capturing two conceptually and observationally distinct dimensions of social capital. In fact, our correlation coefficients are even visibly lower than in several studies based on other empirical operationalizations (see e.g., Halpern 2005).

Having identified the intra-country variation in our variables, let us now identify the most apparent similarities and differences between the eight CEECs at the country level.

\subsection{Similarities and Differences Among CEECs}

Already the first glance at country averages, depicted in Fig. 2, confirms that CEECs are heterogeneous in terms of their social capital resources (Kääriäinen and Lehtonen 2006; Wallace and Pichler 2007; Alesina and Giuliano 2010). The leaders of the region in terms of bridging social capital are Estonia and Slovenia, and the leader in terms of bonding social capital is Poland. We also can see in Fig. 2 that at the international level, bridging social capital and bonding social capital seem to be rather independent dimensions of social capital, which is congruent with Putnam (2000).
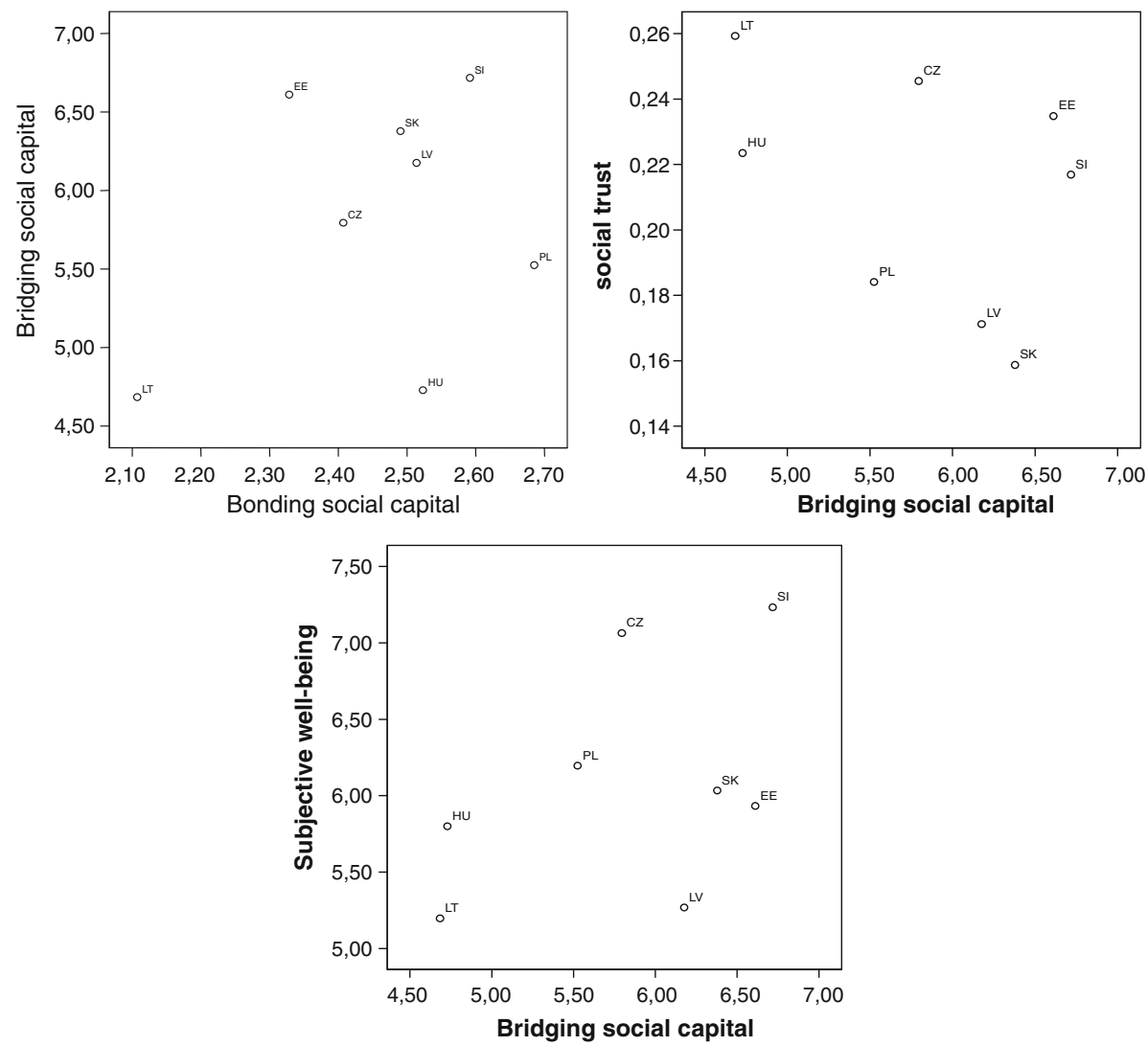

Fig. 2 Bridging and bonding social capital stocks, trust and happiness: CEE country averages 
Furthermore, the societies of Slovenia and Czech Republic are relatively happiest, whereas the Latvians and Lithuanians are least happy. For the second time Slovenia appears to be a leader of the region here-both in terms of bridging social capital and happiness.

As regards the cross-country relationship between bridging social capital and social trust, these two phenomena do not appear to be positively correlated (somewhat contrasting with the predictions of underlying sociological theories). Instead, we see two distinct groups of countries: the (marginally) more trusting are the Lithuanians, Czechs, Estonians, Hungarians, and Slovenes. The most distrustful are the Slovaks, Latvians, and Poles. The possible reason for this finding is that there might exist substantial country-specific factors interfering with this relationship. Indeed, correlation analysis at the individual level confirms a positive relationship between bridging social capital and trust.

In sum, scatterplots presented in Fig. 2 indicate that CEE countries are clearly heterogeneous in terms of their social background despite some common features (e.g. social trust is uniformly low in all considered countries, much lower than the EU average). Interestingly, there are both "leaders" and "laggards" in social development in the region and our task here is to investigate the factors responsible for their position in the region, and the mechanisms which may lead to persistence of these observed patterns. Naturally, it must be remembered that country-level averages hide vast intra-country heterogeneity in social capital patterns and social trust, a feature which we will take into account in our econometric investigation.

\section{The Joint Impact of Social Capital, Trust and Earnings on Individuals' Happiness}

Let us now pass to the main results of the current study. The key explanatory variables of our cross-sectional regressions explaining individuals' happiness-bridging and bonding social capital, own social trust and average social trust in the reference group-have been chosen in line with the underlying social capital literature as well as the implications of the theoretical model, developed in a closely related paper (Growiec and Growiec 2013). We have also included a number of control variables in these regressions, found to have a significant impact on the dependent variables, such as individuals' earnings, education, age, size of town of residence, etc. We have been very careful with the treatment of endogeneity, which-alongside potential omitted variables bias-turns out to be the crucial empirical problem here. In result, all "central" equations of this paper have been estimated with the instrumental variables (IV) technique.

Our main results, summarized in Table 4, are as follows. Primarily we find that, other things equal, both bridging and bonding social capital have a positive impact on happiness. We conclude that people in CEECs accumulate happiness both by maintaining contacts with non-kin and with kin. This result is robust across all specifications included in Table 4.

Although it is an admittedly hard task to find good (i.e., both exogenous and strong) instruments for bridging and bonding social capital in cross-sectional data, our final results indicate that we have succeeded in finding such variables. Our final list includes: number of children, three measures of religiosity (survey questions: "How often do you attend religious services?", "Do you get comfort and strength from religion?", and "Is religion important in your life?"), one measure of interest in politics (survey question: "How often do you discuss political matters with friends?"), a range of dummy variables characterizing the respondent's membership in organizations, and a range of dummy variables on what 


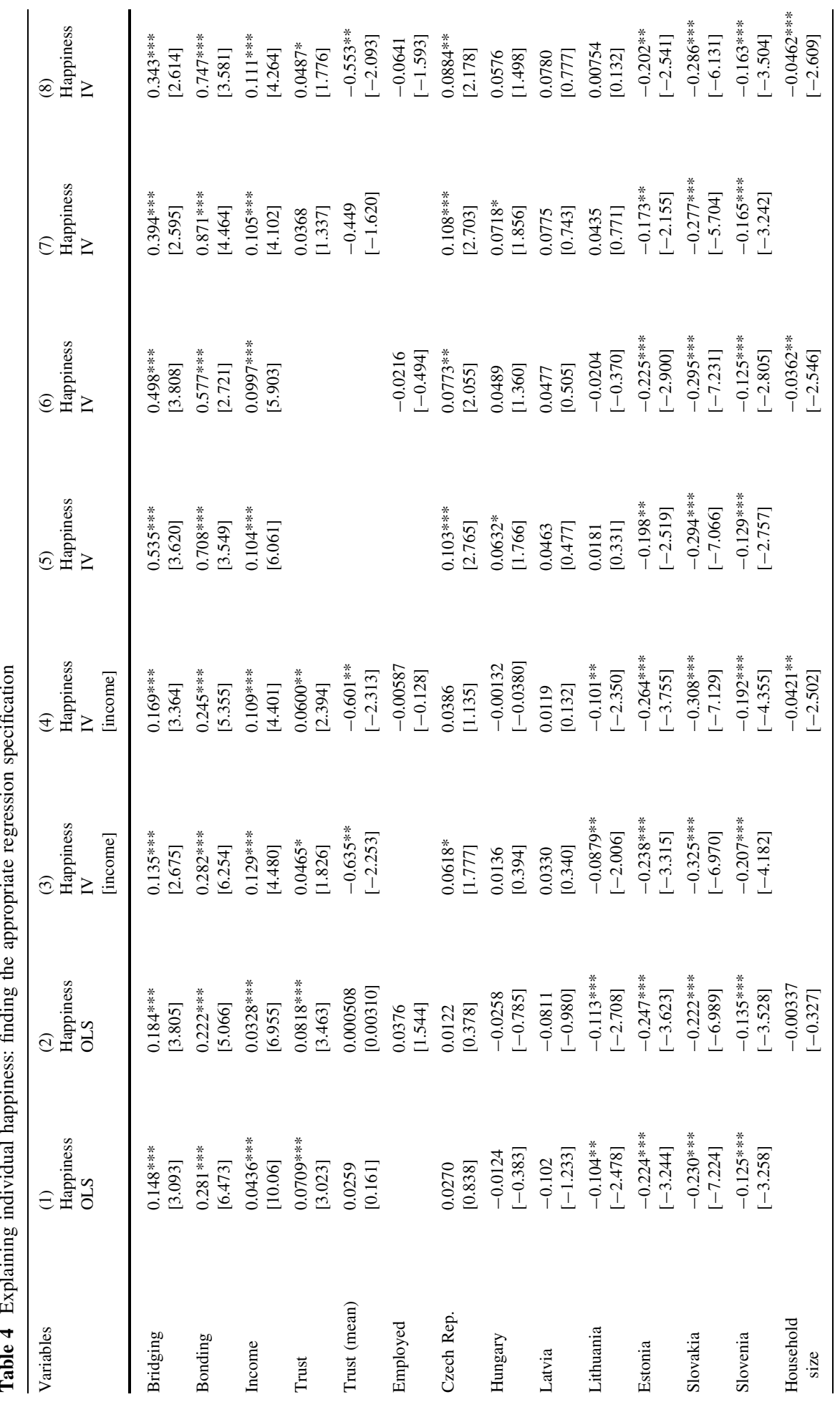




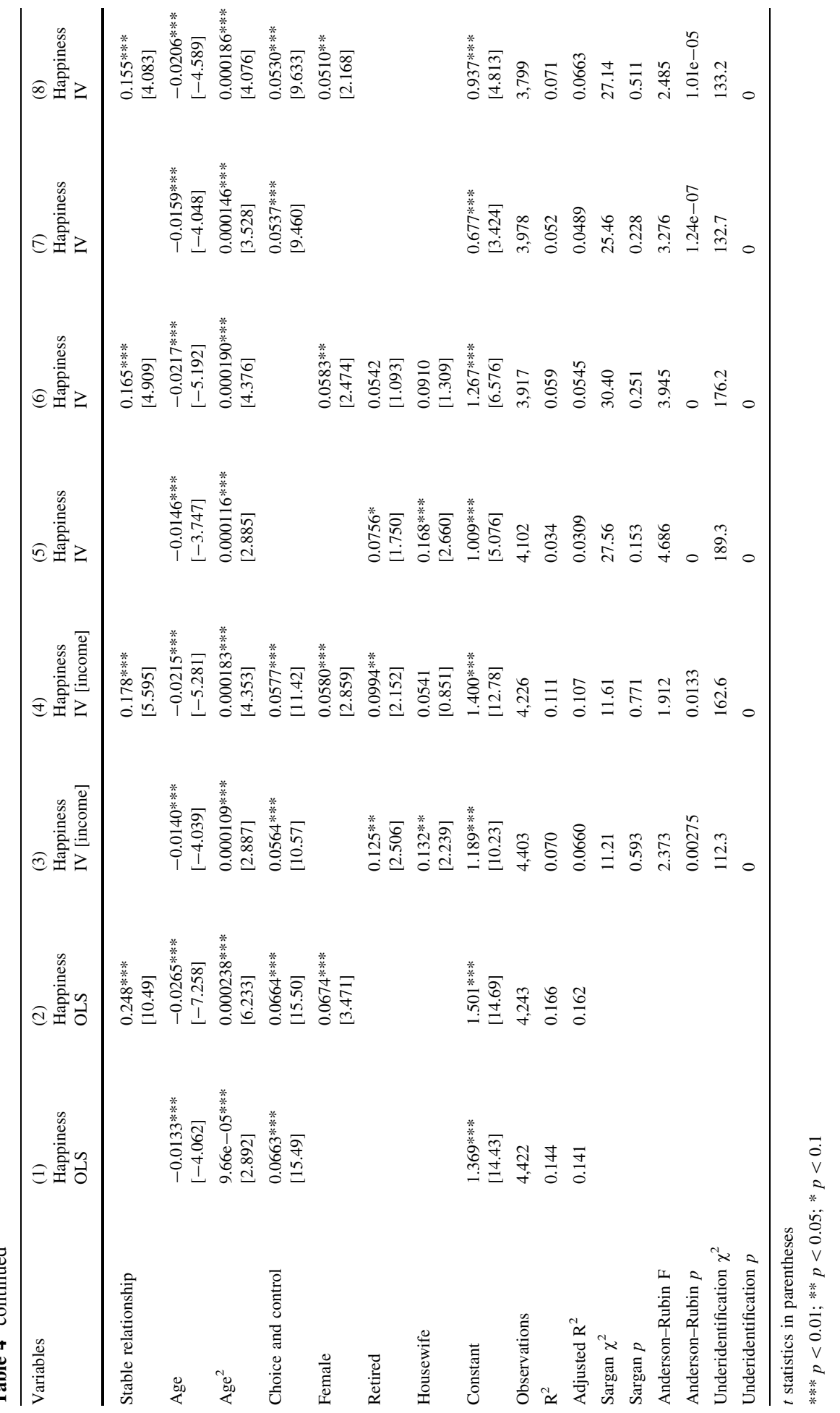


she perceives to be important child qualities (good manners, independence, hard work, honesty, imagination, obedience, etc.). In order to simultaneously capture the endogeneity of individuals' earnings, we also used as instruments: individuals' education, size of town of residence, number of children, the status of a student, retired person, and housewife.

The IV procedure has been carried out in the following way. ${ }^{4}$ We begin with estimating first-stage regression equations where the three endogenous regressors (bridging and bonding social capital, earnings) are taken as dependent variables, and the aforementioned set of exogenous instruments as well as the exogenous regressors included also in the main regression equation - are taken as independent variables. First-stage equations are estimated with OLS in a reduced-form system, which allows the error terms to be correlated between the equations. The theoretical values from this model are stored for later use in the second stage. In the second stage, we set up the main regression equation explaining happiness, including these theoretical values instead of the endogenous regressors alongside the exogenous regressors. Our first-stage regression results (not reported) indicate that, in line with the associated literature, bridging social capital is determined in CEECs primarily by membership in organizations, ${ }^{5}$ interest in politics (Putnam 2000), imagination as an important child quality (Growiec 2011), as well as student status, church attendance, town size (negative impact), and number of children (negative impact). Bonding social capital, on the other hand, is determined largely by the number of children (stronger family ties go together with higher fertility, Alesina and Giuliano 2010), good manners, hard work and obedience as important child qualities (Growiec 2011), independence and imagination as important child qualities - with a negative sign, all three measures of religiosity, and gender [on average, women have stronger kinship ties (Alesina and Giuliano 2010)].

The results of Sargan tests indicate that our instruments are valid, whereas underidentification tests prove that our auxiliary regressions are able to identify the endogenous regressors correctly with instruments. Anderson-Rubin tests indicate that both endogenous variables are jointly significant in the main equation. At the same time, $\chi^{2}$ endogeneity tests confirm that bridging and bonding social capital are indeed correlated with the error term of the OLS regression, and thus OLS results are biased because of endogeneity.

When going from left to right in Table 4, we observe increasing complexity of the estimation technique. At the same time, more and more control variables are included in the regressions. The simplest models (1)-(2) are likely to lead to biased estimates because of regressor endogeneity and omitted variables. In models (3)-(4) we use the IV technique to capture the endogeneity of individuals' incomes. In models (5)-(6) we address the endogeneity of social capital variables as well, but we do not account for the simultaneous impact of social trust. Models (7)-(8) control for all aforementioned issues. In each "pair" of specifications mentioned above, the former does not include several important conditioning variables such as employment status, gender, household size, and whether the respondent is in a stable relationship, and the latter does. Model (8) in Table 4 is our preferred specification because it captures endogeneity of social capital and earnings, controls for the largest number of exogenous determinants of happiness, and passes all relevant econometric tests, including the Sargan test for instrument validity and the underidentification test for instrument relevance.

\footnotetext{
4 Technically, we have used the Stata command ivreg2.

5 Membership in seven types of organizations has been identified as statistically significant determinants of bridging social capital: (1) social welfare service for the elderly, (2) religious organization, (3) education, arts, music, cultural activities, (4) youth work, (5) sports or recreation, (6) organization concerned with health, (7) other organizations.
} 
Our results are the following. First, we find that other things equal, both bridging and bonding social capital increase individuals' happiness. This may be due to the fact that people who have social contacts are generally happier than those who don't have them, regardless of whom they keep in touch with (Diener and Seligman 2002). It is also likely that more detailed measures of happiness are needed to identify the differences between the impacts of contacts with kin and non-kin in this respect (Growiec 2011).

We also find that individuals' trust is generally positively related to happiness, even if one controls for social capital and earnings, but the mean level of trust in one's reference group exerts a negative impact on their happiness. ${ }^{6}$

When it comes to our control variables, we analyzed the impact on happiness of earnings, gender, age, age ${ }^{2}$, income, employment status, household size, retired status, housewife status, perceived freedom of choice and control, and being in a stable relationship. Individuals' incomes are found to have a positive impact on one's happiness. Household size (number of adult persons in the household) has a negative impact on happiness, indicating that other things equal, living together with extended family lowers one's happiness. The results regarding retirement and housewife status are mildly indicative of a positive relationship but not robust.

As far as further control variables are concerned, women are more satisfied with their lives then men. This result holds here specifically because of the large set of control variables we use (including, e.g., household size and income): in fact, women are significantly less happy than men in raw data.

The relationship between age and happiness is $U$ shaped which means that young and old people are generally happier then people in their middle age. This finding is in good agreement with the established literature.

We also find that individuals who experience more freedom of choice and control are significantly more satisfied with their lives than those who do not. This finding likely relates to the historical background of CEE countries which underwent transition from communist regimes to democracy and market economy (see Sztompka 1996, 2004, for discussions).

We also find that people in a stable relationship are significantly more satisfied with their lives - a result in line both with conventional knowledge and earlier research (e.g. Pahl and Pevalin 2005). A little surprisingly, it is also found that controlling for incomes, employment status does not have any significant impact on happiness.

As is visible in Table 5, we find no direct evidence of interactions between social capital, trust, and employment status in explaining happiness. Model (8) in Table 4, reproduced as model (4) in Table 5, delivers essentially the same results as models including interaction terms. On the other hand, it must be kept in mind, that the instruments used in these regressions, although valid and relevant, are relatively weakly correlated with the endogenous interaction terms. Hence, it might also be the case that some interactions are important in reality, only that our instruments fail to identify these effects.

Since the construction of the survey scale of happiness in WVS is the same across all countries, we can also interpret the coefficients on country dummies. Our reference country is Poland, and therefore a positive sign on a country dummy implies that citizens of that country are, on average, and controlling for differences in all other characteristics included in the regression, happier than the Poles. Such "residual happiness" is found to be positive in the Czech Republic, and negative in Slovakia, Estonia, and Slovenia.

\footnotetext{
${ }^{6}$ This last result is somewhat puzzling from the interpretational perspective as well as not robust to changes in the estimation methodology.
} 


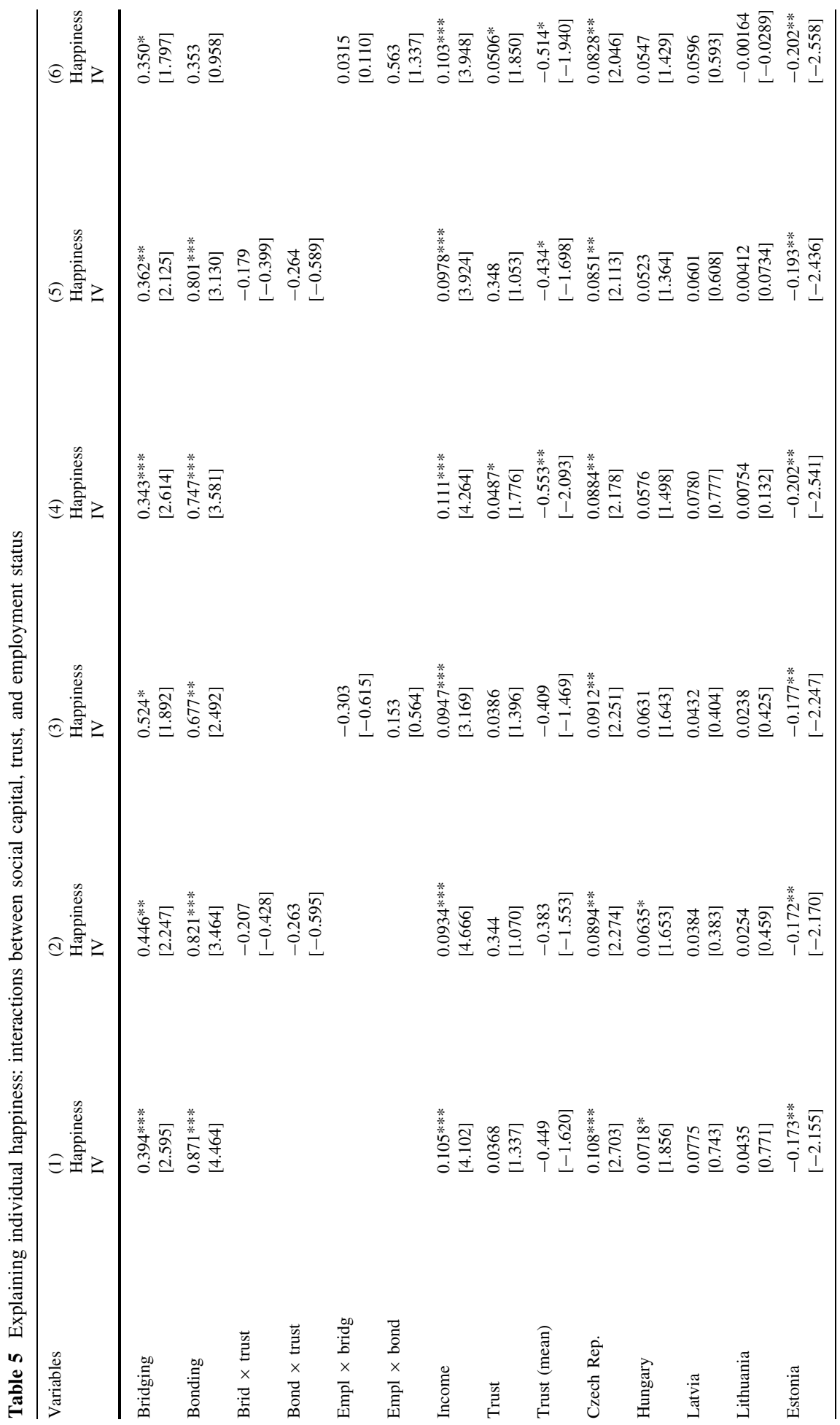




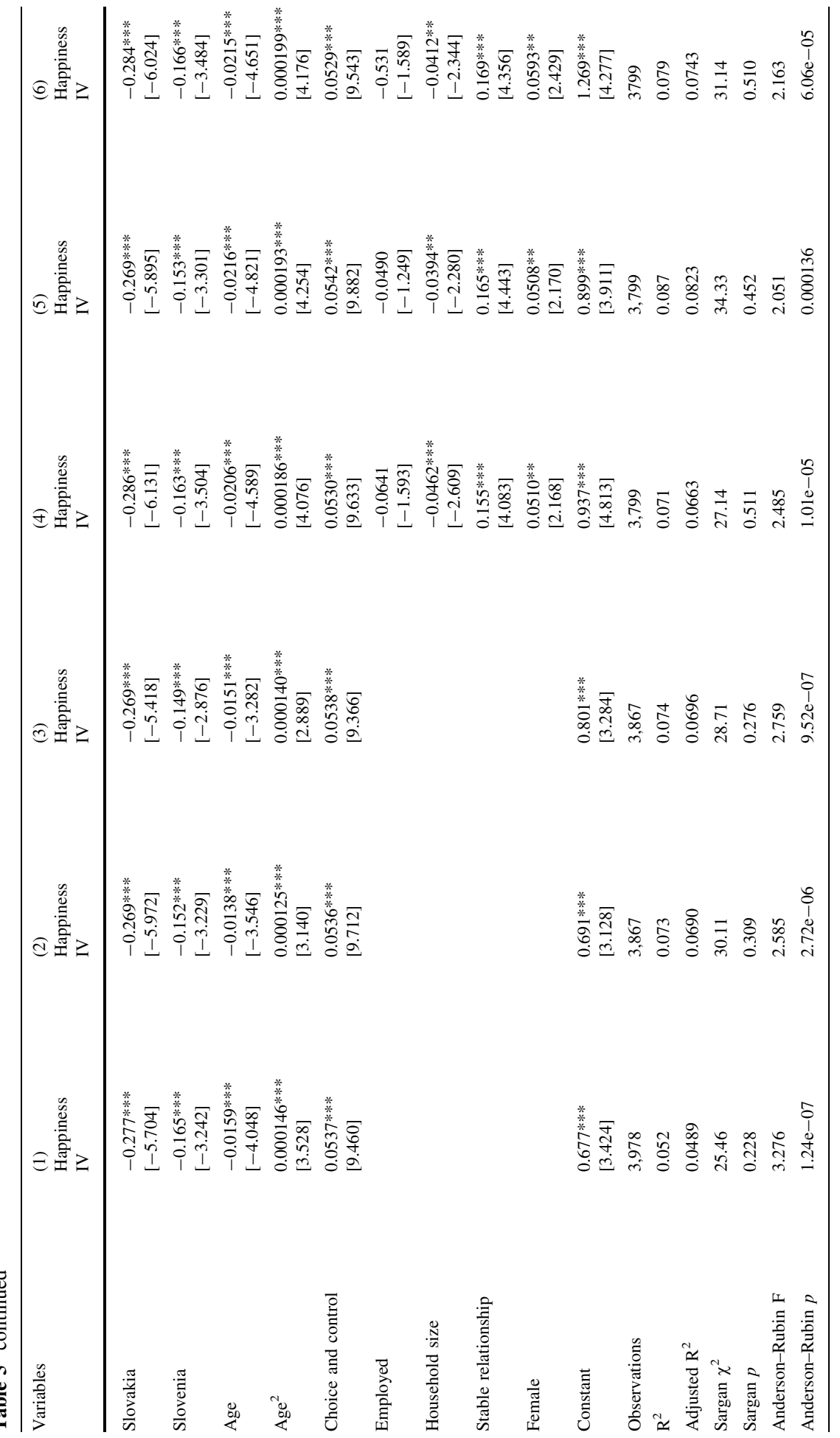




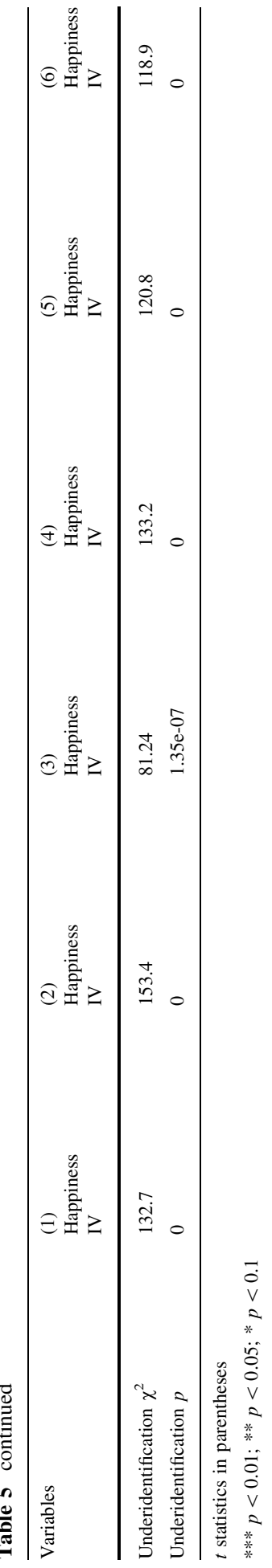




\section{Robustness Checks}

\subsection{Happiness Versus Life Satisfaction}

As an important robustness check, we proceed to replace the dependent variable happiness with the WVS measure of life satisfaction. Indeed, as argued e.g. by Gamble and Gärling (2012), life satisfaction captures a more long-term component of individual well-being than happiness. As these authors argue, happiness is in fact partly a "situation-dependent evaluation of hedonic experiences, specifically the valence and activation of current mood" (which can be highly variable), and partly it is related to cognitive judgments of individuals' life satisfaction (which are much more persistent). Since social capital is also persistent (Putnam 2000), it is interesting to assess its impact on life satisfaction.

It turns out that our main results remain essentially unaffected by replacing happiness as the dependent variable with life satisfaction-as demonstrated in Table 6. This result emphasizes the robustness of our main set of regression results, summarized in Table $4 .^{7}$ The only visible differences are related to social trust: while only marginally significant in happiness regressions, individual social trust becomes a strongly significant determinant of life satisfaction, with an unambiguously positive sign. Furthermore, our somewhat puzzling result that trustworthiness (i.e., the mean level of trust in one's reference group) may have a negative impact on happiness disappears when life satisfaction is the explained variable. The estimated coefficient on trustworthiness is positive but statistically insignificant. Finally, we also note that housewife status (even when controlling for gender) tends to have a significantly positive impact on life satisfaction, but not happiness.

\subsection{Instrumental Variables Ordered Probit Estimates}

Let us now also confirm that our results are not driven by the linear estimation method, which has been applied here even though the dependent variable-the WVS measure of happiness - is an ordinal rating scale with just four available options. Corroborating and extending the celebrated results by Ferrer-i-Carbonell and Frijters (2004), we find that imposing linearity does not in fact have an important impact on our econometric results. To obtain this result, we have re-estimated three among our main OLS/IV regressions, summarized as models (2), (7) and (8) in Table 4, with ordered probit and instrumental variables ordered probit estimation techniques. ${ }^{8}$ Upon inspecting these estimates, summarized in Table 7, please keep in mind that due to a different model specification, the magnitudes of estimated coefficients in ordered probit models are not directly comparable to the ones obtained using OLS/IV. However, relative magnitudes as well as their statistical significance are reassuring that our main regression results are robust to this modification. The only notable differences are that in our IV ordered probit regressions, individual social trust turns out statistically significant and beneficial for happiness at the $1 \%$ significance level; the negative impact of household size, on the other hand, loses its significance.

\footnotetext{
7 We have also re-estimated Table 5 with life satisfaction instead of happiness as the explained variable. Our main results have again proven robust to this modification. We do not include the results here to save space; they are available from the authors upon request.

${ }^{8}$ We used the Stata command oprobit as well as the user-supplied command $\mathrm{cmp}$.
} 


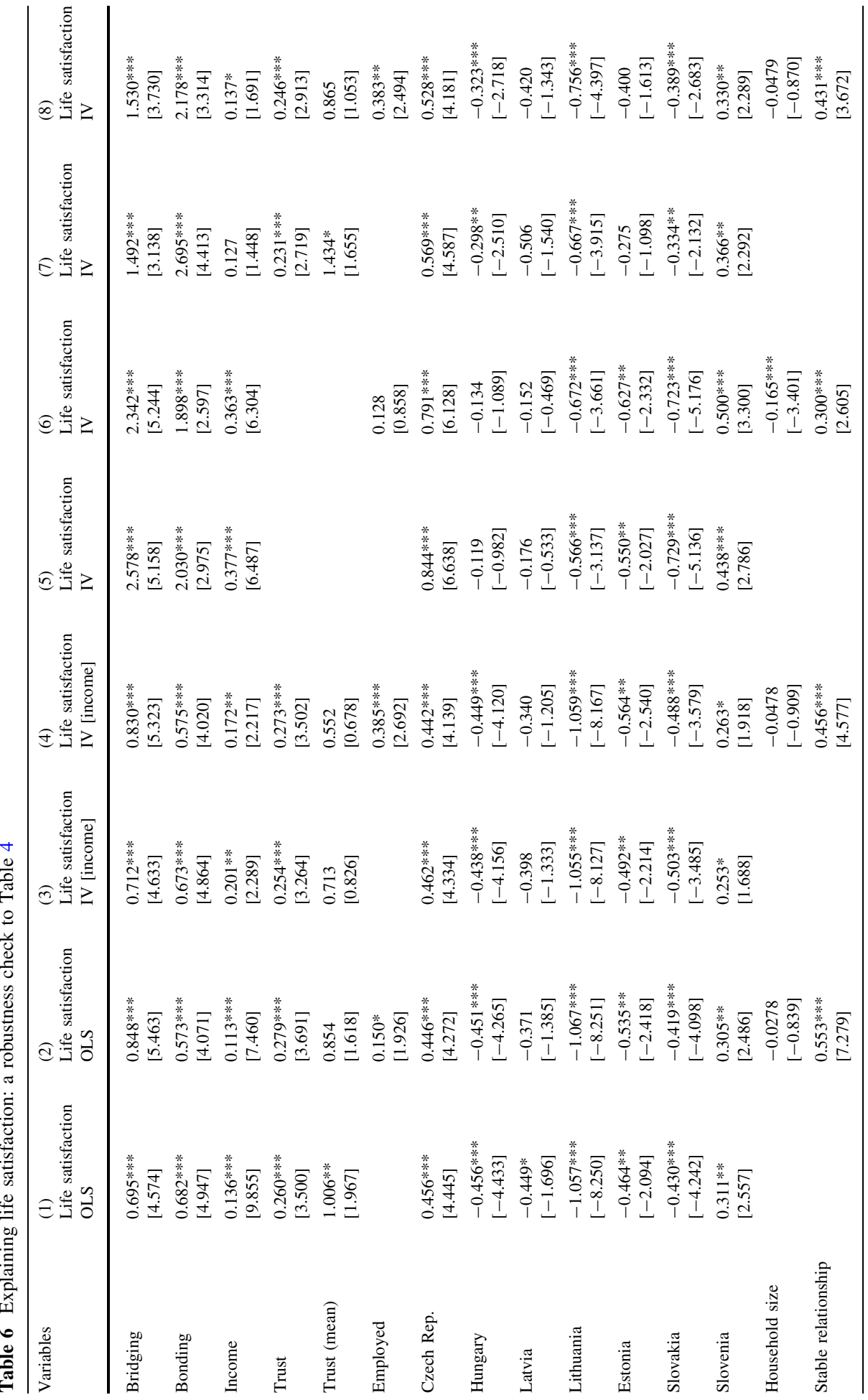




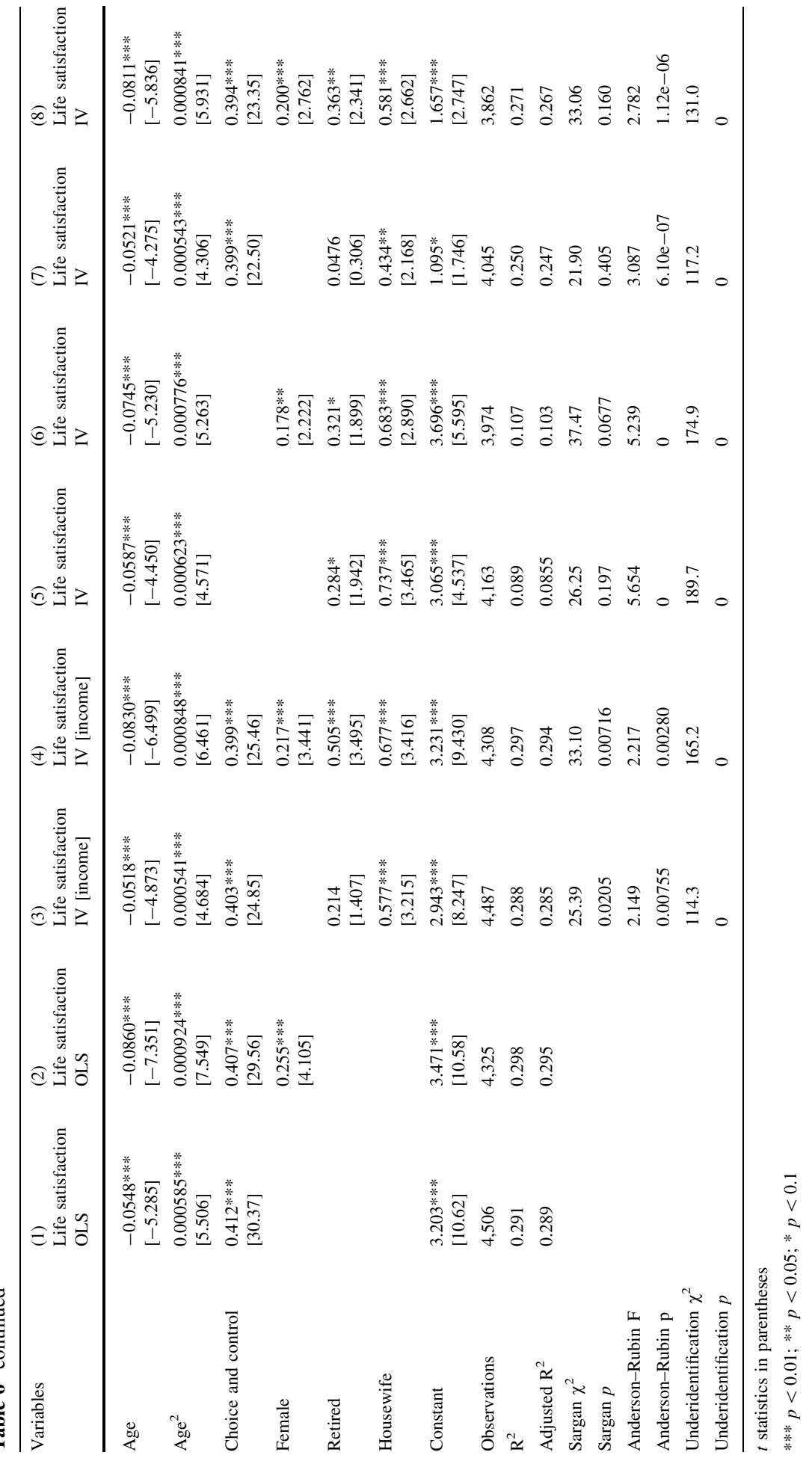


Table 7 Explaining happiness: linear versus ordered probit estimates

\begin{tabular}{|c|c|c|c|c|c|c|}
\hline Variables & $\begin{array}{l}\text { (1) } \\
\text { Happiness } \\
\text { OLS }\end{array}$ & $\begin{array}{l}(2) \\
\text { Happiness } \\
\text { o-Probit }\end{array}$ & $\begin{array}{l}\text { (3) } \\
\text { Happiness } \\
\text { IV }\end{array}$ & $\begin{array}{l}\text { (4) } \\
\text { Happiness } \\
\text { IV o-probit }\end{array}$ & $\begin{array}{l}(5) \\
\text { Happiness } \\
\text { IV }\end{array}$ & $\begin{array}{l}\text { (6) } \\
\text { Happiness } \\
\text { IV o-probit }\end{array}$ \\
\hline Bridging & $\begin{array}{l}0.184 * * * \\
{[3.805]}\end{array}$ & $\begin{array}{l}0.575^{* * *} \\
{[3.479]}\end{array}$ & $\begin{array}{l}0.394 * * * \\
{[2.595]}\end{array}$ & $\begin{array}{l}0.606^{* * *} * \\
{[3.770]}\end{array}$ & $\begin{array}{l}0.343 * * * \\
{[2.614]}\end{array}$ & $\begin{array}{l}0.730 * * * \\
{[4.381]}\end{array}$ \\
\hline Bonding & $\begin{array}{l}0.222 * * * \\
{[5.066]}\end{array}$ & $\begin{array}{l}0.739 * * * \\
{[5.049]}\end{array}$ & $\begin{array}{l}0.871 * * * \\
{[4.464]}\end{array}$ & $\begin{array}{l}0.933 * * * \\
{[5.145]}\end{array}$ & $\begin{array}{l}0.747 * * * \\
{[3.581]}\end{array}$ & $\begin{array}{l}0.691 * * * \\
{[3.628]}\end{array}$ \\
\hline Income & $\begin{array}{l}0.0328 * * * \\
{[6.955]}\end{array}$ & $\begin{array}{l}0.108 * * * \\
{[6.696]}\end{array}$ & $\begin{array}{l}0.105 * * * \\
{[4.102]}\end{array}$ & $\begin{array}{l}0.0862 * * * \\
{[4.303]}\end{array}$ & $\begin{array}{l}0.111 * * * \\
{[4.264]}\end{array}$ & $\begin{array}{l}0.0767 * * * \\
{[3.434]}\end{array}$ \\
\hline Trust & $\begin{array}{l}0.0818^{* * *} \\
{[3.463]}\end{array}$ & $\begin{array}{l}0.287 * * * \\
{[3.560]}\end{array}$ & $\begin{array}{l}0.0368 \\
{[1.337]}\end{array}$ & $\begin{array}{l}0.122 * * * \\
{[2.802]}\end{array}$ & $\begin{array}{l}0.0487 * \\
{[1.776]}\end{array}$ & $\begin{array}{l}0.143 * * * \\
{[3.174]}\end{array}$ \\
\hline Trust (mean) & $\begin{array}{l}0.000508 \\
{[0.00310]}\end{array}$ & $\begin{array}{l}-0.00920 \\
{[-0.0165]}\end{array}$ & $\begin{array}{l}-0.449 \\
{[-1.620]}\end{array}$ & $\begin{array}{l}-0.0168 \\
{[-0.0491]}\end{array}$ & $\begin{array}{l}-0.553 * * \\
{[-2.093]}\end{array}$ & $\begin{array}{l}-0.162 \\
{[-0.459]}\end{array}$ \\
\hline Employed & $\begin{array}{l}-0.0265 * * * \\
{[-7.258]}\end{array}$ & $\begin{array}{l}0.126 \\
{[1.534]}\end{array}$ & & & $\begin{array}{l}-0.0641 \\
{[-1.593]}\end{array}$ & $\begin{array}{l}0.0379 \\
{[0.735]}\end{array}$ \\
\hline Czech Rep. & $\begin{array}{l}0.0376 \\
{[1.544]}\end{array}$ & $\begin{array}{l}0.00576 \\
{[0.0521]}\end{array}$ & $\begin{array}{l}0.108 * * * \\
{[2.703]}\end{array}$ & $\begin{array}{l}0.0710 \\
{[1.166]}\end{array}$ & $\begin{array}{l}0.0884 * * \\
{[2.178]}\end{array}$ & $\begin{array}{l}0.0336 \\
{[0.537]}\end{array}$ \\
\hline Hungary & $\begin{array}{l}0.0122 \\
{[0.378]}\end{array}$ & $\begin{array}{l}-0.0801 \\
{[-0.702]}\end{array}$ & $\begin{array}{l}0.0718 * \\
{[1.856]}\end{array}$ & $\begin{array}{l}0.0352 \\
{[0.583]}\end{array}$ & $\begin{array}{l}0.0576 \\
{[1.498]}\end{array}$ & $\begin{array}{l}0.00691 \\
{[0.110]}\end{array}$ \\
\hline Latvia & $\begin{array}{l}-0.0258 \\
{[-0.785]}\end{array}$ & $\begin{array}{l}-0.375 \\
{[-1.371]}\end{array}$ & $\begin{array}{l}0.0775 \\
{[0.743]}\end{array}$ & $\begin{array}{l}-0.185 \\
{[-1.239]}\end{array}$ & $\begin{array}{l}0.0780 \\
{[0.777]}\end{array}$ & $\begin{array}{l}-0.170 \\
{[-1.117]}\end{array}$ \\
\hline Lithuania & $\begin{array}{l}-0.0811 \\
{[-0.980]}\end{array}$ & $\begin{array}{l}-0.432 * * * \\
{[-3.092]}\end{array}$ & $\begin{array}{l}0.0435 \\
{[0.771]}\end{array}$ & $\begin{array}{l}-0.101 \\
{[-1.218]}\end{array}$ & $\begin{array}{l}0.00754 \\
{[0.132]}\end{array}$ & $\begin{array}{l}-0.147 * \\
{[-1.738]}\end{array}$ \\
\hline Estonia & $\begin{array}{l}-0.113 * * * \\
{[-2.708]}\end{array}$ & $\begin{array}{l}-0.800 * * * \\
{[-3.579]}\end{array}$ & $\begin{array}{l}-0.173 * * \\
{[-2.155]}\end{array}$ & $\begin{array}{l}-0.416 * * * \\
{[-3.301]}\end{array}$ & $\begin{array}{l}-0.202 * * \\
{[-2.541]}\end{array}$ & $\begin{array}{l}-0.493 * * * \\
{[-3.857]}\end{array}$ \\
\hline Slovakia & $\begin{array}{l}-0.247 * * * \\
{[-3.623]}\end{array}$ & $\begin{array}{l}-0.739 * * * \\
{[-6.818]}\end{array}$ & $\begin{array}{l}-0.277 * * * \\
{[-5.704]}\end{array}$ & $\begin{array}{l}-0.425 * * * \\
{[-6.708]}\end{array}$ & $\begin{array}{l}-0.286^{* * *} \\
{[-6.131]}\end{array}$ & $\begin{array}{l}-0.444 * * * \\
{[-6.836]}\end{array}$ \\
\hline Slovenia & $\begin{array}{l}-0.222^{* * *} \\
{[-6.989]}\end{array}$ & $\begin{array}{l}-0.490 * * * \\
{[-3.764]}\end{array}$ & $\begin{array}{l}-0.165^{* * *} \\
{[-3.242]}\end{array}$ & $\begin{array}{l}-0.248 * * * \\
{[-3.377]}\end{array}$ & $\begin{array}{l}-0.163^{* * *} \\
{[-3.504]}\end{array}$ & $\begin{array}{l}-0.281 * * * \\
{[-3.780]}\end{array}$ \\
\hline Age & $\begin{array}{l}-0.135 * * * \\
{[-3.528]}\end{array}$ & $\begin{array}{l}-0.0930 * * * \\
{[-7.450]}\end{array}$ & $\begin{array}{l}-0.0159 * * * \\
{[-4.048]}\end{array}$ & $\begin{array}{l}-0.0247 * * * \\
{[-4.025]}\end{array}$ & $\begin{array}{l}-0.0206 * * * \\
{[-4.589]}\end{array}$ & $\begin{array}{l}-0.0464 * * * \\
{[-6.570]}\end{array}$ \\
\hline $\mathrm{Age}^{2}$ & $\begin{array}{l}-0.00337 \\
{[-0.327]}\end{array}$ & $\begin{array}{l}0.000844 * * * \\
{[6.482]}\end{array}$ & $\begin{array}{l}0.000146^{* * * *} \\
{[3.528]}\end{array}$ & $\begin{array}{l}0.000187 * * * \\
{[2.984]}\end{array}$ & $\begin{array}{l}0.000186 * * * \\
{[4.076]}\end{array}$ & $\begin{array}{l}0.000419 * * * \\
{[5.772]}\end{array}$ \\
\hline $\begin{array}{c}\text { Choice and } \\
\text { control }\end{array}$ & $\begin{array}{l}0.248 * * * \\
{[10.49]}\end{array}$ & $\begin{array}{l}0.230^{* * * *} \\
{[15.13]}\end{array}$ & $\begin{array}{l}0.0537 * * * \\
{[9.460]}\end{array}$ & $\begin{array}{l}0.112 * * * \\
{[13.58]}\end{array}$ & $\begin{array}{l}0.0530 * * * \\
{[9.633]}\end{array}$ & $\begin{array}{l}0.114 * * * \\
{[13.45]}\end{array}$ \\
\hline $\begin{array}{l}\text { Household } \\
\text { size }\end{array}$ & $\begin{array}{l}0.000238 * * * \\
{[6.233]}\end{array}$ & $\begin{array}{l}-0.0137 \\
{[-0.392]}\end{array}$ & & & $\begin{array}{l}-0.0462 * * * \\
{[-2.609]}\end{array}$ & $\begin{array}{l}-0.0204 \\
{[-0.916]}\end{array}$ \\
\hline $\begin{array}{l}\text { Stable } \\
\quad \text { relationship }\end{array}$ & $\begin{array}{l}0.0664 * * * \\
{[15.50]}\end{array}$ & $\begin{array}{l}0.825^{* * * *} \\
{[10.24]}\end{array}$ & & & $\begin{array}{l}0.155^{* * * *} \\
{[4.083]}\end{array}$ & $\begin{array}{l}0.442 * * * \\
{[9.091]}\end{array}$ \\
\hline Female & $\begin{array}{l}0.0674 * * * \\
{[3.471]}\end{array}$ & $\begin{array}{l}0.229 * * * \\
{[3.487]}\end{array}$ & & & $\begin{array}{l}0.0510^{* * *} \\
{[2.168]}\end{array}$ & $\begin{array}{l}0.135 * * * \\
{[3.627]}\end{array}$ \\
\hline
\end{tabular}

$t$ statistics in parentheses

$* * * p<0.01$; ** $p<0.05$; * $p<0.1$

\section{Revisiting Earlier Empirical Findings}

Even though the premises of the current empirical study are rooted in the established theoretical literature, its results can be used to shed some new light on the considered 


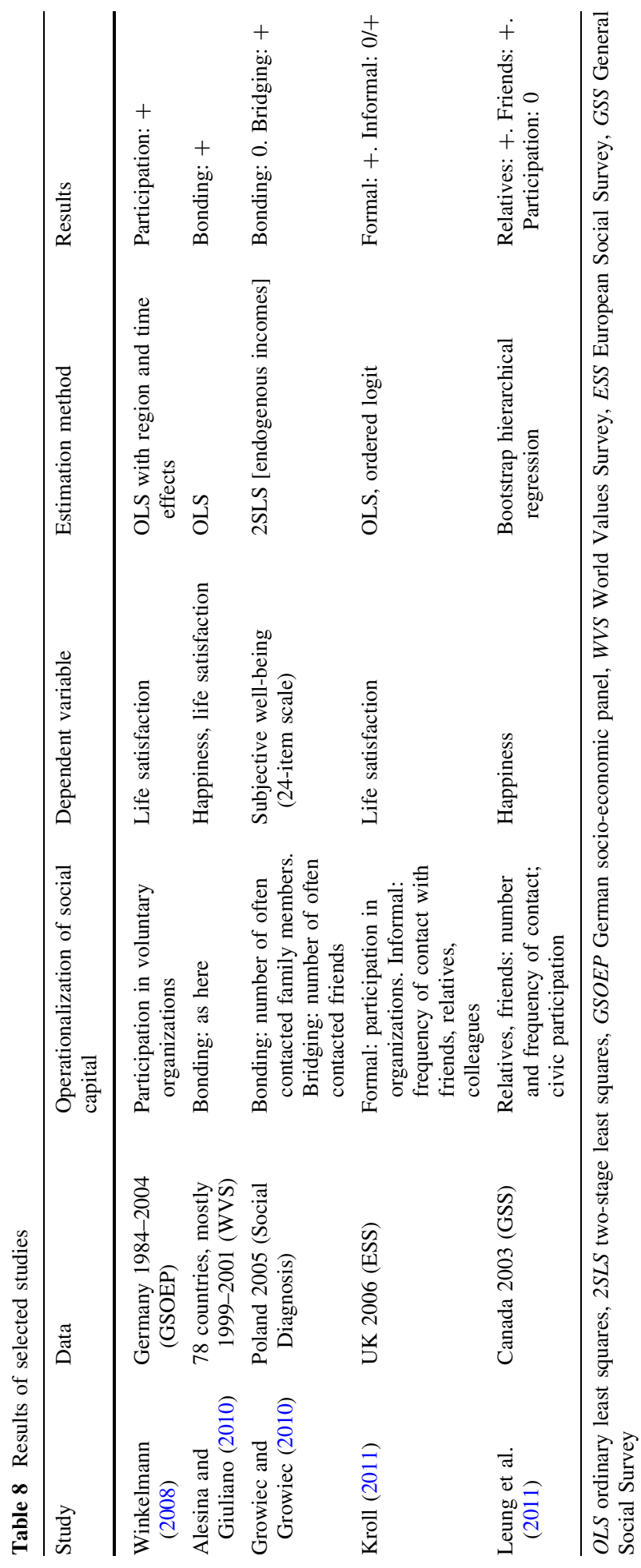


relationships. Thanks to our findings, we are able to place important additional qualifications on some of the widely shared views.

Results of selected contributions where the relationships between social capital and happiness were studied, have been summarized in Table 8 . The list of studies included in the table is meant to be representative, but it is by no means exhaustive. Furthermore, given the multiplicity of empirical definitions of social capital, we decided to review only those studies where similar approaches to ours were adopted, i.e., only those which adopted the network operationalization of social capital, and we were particularly interested in articles acknowledging the distinction between bridging and bonding social capital. For this reason we omitted all studies which either take social trust directly as the key explanatory variable and disregard social capital althogether, and those which include some measures of trust as components of their social capital operationalizations (e.g., Knack and Keefer 1997; Zak and Knack 2001; Elgar et al. 2011). We also omitted studies where social capital measures were based on sociability (e.g., Bjørnskov 2008). In case of some studies, we renamed some variables to keep them as close as possible to the current study. In case the scope of certain studies reached beyond the identification of the social capital-happiness relationship, we limited our attention to this issue only.

Inspection of Table 8 reveals that bonding and bridging social capital are generally found to have a positive impact on individuals' life satisfaction or happiness, irrespective of the data sample and estimation method. The current article confirms this relationship for CEECs, both when endogeneity of social capital stocks and income is controlled for and when it is disregarded. Further related empirical literature indicates also that social trust tends to be positively correlated with happiness, even when controlling for a very wide range of other individual characteristics including social capital measures (e.g., Elgar et al. 2011). Based on CEEC data, we qualify this finding, indicating that once (endogenously determined) social capital and earnings are properly instrumented for, the impact of trust on happiness loses its significance, and the impact of average trust in the individual's group of reference may even turn out negative (although the last finding is not robust), whereas the impact of social capital on happiness remains positive and strong.

\section{Conclusion}

The current paper has investigated the joint impact of bridging and bonding social capital, social trust and earnings on individuals' self-reported happiness, based on WVS 2000 data for Central and Eastern European countries. We have found that both bridging and bonding social capital exert a positive effect on individuals' happiness. The broad relationships identified here are also robust to the inclusion of a range of personal characteristics (such as earnings, education, size of town of residence, the degree of freedom of choice and control, living in a stable relationship, etc.) as control variables in the regressions.

The primary methodological contribution of the current paper has been to sort out the endogeneity and omitted variables bias issues, often overlooked in the related literature. We find these problems to be actually quite serious in the context of analyses of the impact of social capital, trust, and earnings on happiness. When these problems are not adequately addressed, one can likely obtain spurious results.

Our results can also be interpreted from a complementary point of view. Namely, they also arguably provide a refinement of our understanding of social change processes in postcommunist countries. In particular, our results partially align with the hypothesis of existence of a "low trust trap" in CEECs, where the stocks of bridging social capital and 
social trust are persistently low, creating a vicious circle ("trusting only whom you know, knowing only whom you trust"), leading to relatively low levels of self-reported happiness.

Acknowledgments This research was supported by a grant from the CERGE-EI Foundation under a program of the Global Development Network, administered by the Institute for Structural Research, Warsaw, Poland. All opinions expressed here are those of the authors and have not been endorsed by CERGEEI, the GDN, or the institutions the authors are affiliated with. The authors thank an anonymous Referee, Tom Coupé, Randall Filer, Peter Katuščák, Zuzana Fungáčová, and participants of the GDN Workshop (Prague 2009) for their helpful comments and suggestions which helped significantly improve the paper.

Open Access This article is distributed under the terms of the Creative Commons Attribution License which permits any use, distribution, and reproduction in any medium, provided the original author(s) and the source are credited.

\section{References}

Alesina, A., \& Giuliano, P. (2010). The power of family. Journal of Economic Growth, 15(2), 93-125.

Beugelsdijk, S., \& Smulders, S. (2003). Bonding and bridging social capital: Which type is good for economic growth? In W. Arts, L. Halman \& J. Hagenaa (Eds.), The cultural diversity of European unity (pp. 147-184). Brill: Leiden.

Bjørnskov, C. (2008). Social capital and happiness in the United States. Applied Research in Quality of Life, $3,43-62$.

Bourdieu, P. (1986). The forms of capital. In J. C. Richardson (Ed.), Handbook of theory and research of sociology of education (pp. 117-142). New York: Greenwood Press.

Burt, R. S. (2005). Brokerage and closure. Oxford: Oxford University Press.

Burt, R. S. (2010). Neighbor networks: Competitive advantage local and personal. Oxford: Oxford University Press.

Christakis, N. A., \& Fowler, J. H. (2009a). Connected: The surprising power of our social networks and how they shape our lives. New York: Little, Brown.

Christakis, N. A., \& Fowler, J. H. (2009b). Dynamic spread of happiness in a large social network: Longitudinal analysis of the Framingham heart study social network. British Medical Journal, 338(7685), 23-27.

Diener, E., \& Seligman, M. E. P. (2002). Very happy people. Research report. Psychological Science, 13(1), $81-84$.

Diener, E., Suh, E. M., Lucas, R. E., \& Smith, H. L. (1999). Subjective well-being: Three decades of progress. Psychological Bulletin, 125, 276-302.

Elgar F. J., Davis, C. G., Wohl, M. J., Trites, S. J., Zelenski, J. M., Martin, M. S. (2011). Social capital, health and life satisfaction in 50 countries. Health and Place, 17, 1044-1053.

Ferrer-i Carbonell, A., \& Frijters, P. (2004). How important is methodology for the estimates of the determinants of happiness? Economic Journal, 114, 641-659.

Fidrmuc, J. (2012). How persistent is social capital? CEDI Discussion Paper Series 12-04, Brunel University.

Gamble, A., \& Gärling, T. (2012). The relationships between life satisfaction, happiness, and current mood. Journal of Happiness Studies, 13, 31-45.

Giddens: (1991). Modernity and self-identity. Self and society in the late modern age. Oxford: Blackwell.

Glanville, J. L., \& Paxton, P. (2007). How do we learn to trust? A confirmatory tetrad analysis of the sources of generalized trust. Social Psychology Quarterly, 70(3), 230-242.

Granovetter, M. S. (1973). The strength of weak ties. American Journal of Sociology, 78(6), 1360-1380.

Growiec, J., \& Growiec, K. (2010). Social capital, well-being, and earnings: Theory and evidence from Poland. European Societies, 12(2), 231-255.

Growiec, K. (2009). Zwịazek mịedzy sieciami społecznymi a zaufaniem społecznym-mechanizm wzajemnego wzmacniania? [The relationship between social networks and social trust: A mutually reinforcing mechanism]? Psychologia spoteczna, 1-2, article 4.

Growiec, K. (2011). Kapitat społeczny. Geneza i spoteczne konsekwencje [Social capital. Origins and social consequences]. Warsaw: Academica.

Growiec, K., \& Growiec, J. (2013). Social capital, trust, and multiple equilibria in economic performance. Macroeconomic Dynamics (forthcoming). 
Halpern, D. (2005). Social capital. Cambridge, Malden: Polity.

Helliwell, J. (2003). How's life-Combining individual and national variables to explain subjective wellbeing. Economic Modeling, 20(2), 331-360.

Kääriäinen, J., \& Lehtonen, H. (2006). The variety of social capital in welfare state regimes-A comparative study of 21 countries. European Societies, 8(1), 27-57.

Kadushin, C. (2002). The motivational foundation of social networks. Social Networks, 24, 77-91.

Klapwijk, A., \& Van Lange, P. A. M. (2009). Promoting cooperation and trust in "noisy" situations: The power of generosity. Journal of Personality and Social Psychology, 96(1), 83-103.

Knack, S., \& Keefer, P. (1997). Does social capital have an economic payoff? A cross-country investigation. Quarterly Journal of Economics, 112(4), 1251-1288.

Kroll, C. (2011). Different things make different people happy: Examining social capital and subjective well-being by gender and parental status. Social Indicators Research, 104, 157-177.

Leonard, M. (2008). Social and subcultural capital among teenagers in Northern Ireland. Youth and Society, 40(2), 224-244.

Leung, A., Kier, C., Fung, T., Fung, L., \& Sproule, R. (2011). Searching for happiness: The importance of social capital. Journal of Happiness Studies, 12, 443-462.

Li, Y., Pickles, A., \& Savage, M. (2005). Social capital and social trust in Britain. European Sociological Review, 21(2), 109-123.

Lin, N. (2001). Social capital. Cambridge: Cambridge University Press.

Pahl, R., \& Pevalin, D. J. (2005). Between family and friends: A longitudal study of friendship choices. British Journal of Sociology, 56(3), 433-450.

Podolny, J. M., \& Baron, J. N. (1997). Resources and relationships: Social networks and mobility in the workplace. American Sociological Review, 62, 673-693.

Putnam, R. (2000). Bowling alone. Collapse and revival of American community. New York: Simon Schuster.

Putnam, R., Leonardi, R., \& Nanetti, R. (1993). Making democracy work: Civic traditions in modern Italy. Princeton: Princeton University Press.

Simmel, G. (1950). The isolated individual and the dyad. In K. Wolff (Ed.), The sociology of Georg Simmel (pp. 118-144). New York: Free Press.

Simmel, G. (1971). Sociability. In D. N. Levine (Ed.), Georg Simmel on individuality and social forms. Chicago: University of Chicago Press.

Słomczyński, K., \& Tomescu Dubrow, I. (2005). Friendship patterns and upward mobility: A test of social capital hypothesis. Polish Sociological Review, 151(3), 221-235.

Sztompka, P. (1996). Looking back: The year 1989 as a cultural and civilizational break. Communist and Post-communist Studies, 29(2), 115-129.

Sztompka, P. (1999). Trust: A sociological theory. Cambridge: Cambridge University Press.

Sztompka, P. (2004). The trauma of social change. In L. Alexander, R. Eyerman, B. Giesen, N. Smelser, P. Sztompka (Eds.), Cultural trauma and collective identity (pp. 155-197). Berkeley: California University Press.

Wallace, C., \& Pichler, F. (2007). Bridging and bonding social capital: Which is more prevalent in Europe? European Journal of Social Security, 9(1), 29-54.

Winkelmann, R. (2008). Unemployment, social capital, and subjective well-being. Journal of Happiness Studies, 10, 421-430.

Yamagishi, T. (2002). The structure of trust: An evolutionary game of mind and society. Hokkaido: Hokkaido University Press.

Zak, P., \& Knack, S. (2001). Trust and growth. Economic Journal, 111(470), 295-321. 